\title{
ОСНОВНЫЕ ЭТАПЫ ПО УПРАВЛЕНИЮ МИГРАЦИОННЫМИ ПРОЦЕССАМИ В РЕСПУБЛИКЕ МОЛДОВА В ПЕРИОД 1990-2020 гг. ${ }^{1}$
}

\author{
Ольга Поалелунжь 둘, научный сотрудник \\ Центр Демографических исследований, \\ Национальный Институт Экономических Исследований, \\ Республика Молдова
}

DOI: https://doi.org/10.36004/nier.cdr.2021.15-23

\begin{abstract}
The article examines and analyzes the main stages of the legal regulation of external migration processes by the Republic of Moldova, since the formation of statehood: from 1992 to the present.

Attention is paid to the tendencies of migration processes, their influence on the development of the national legal framework, changes in state approaches to their management: from prohibitive norms to an integrated approach to the regulation of external migration processes.

At the same time, since migration has complex and global nature, is not only a national but also a regional problem, the article also notes the aspects of transposing into national legislation a part of the European Union Directives in the field of migration, adopted by the country to ensure the visa-free movement of citizens of the Republic of Moldova in the country's EU and EU Association Agreements. Given the significant amount of information, the article reflects legislative changes, without analyzing the changes in government bodies that regulate these processes.
\end{abstract}

Keywords: external migration processes, EU Association Agreements, the national legal framework

\section{JEL Classification: J11}

Миграции населения Республики Молдова на рубеже XX - начале XXI веков, вызванная политическими и экономическими преобразованиями вследствие распада советского лагеря, существенно повлияли на экономические, социальные и демографические процессы в нашей стране. Отсутствие на начальном этапе собственного национального опыта управления, особенно в вопросах внешней миграции, привело к фрагментации и непоследовательности принимаемых решений, к упущению ряда возможностей более эффективного управления процессами.

Также повлияли на принятие комплексных решений такие особенности как наличие территориальной раздробленности страны в результате вооруженного конфликта 1992 г., разно-векторная

\footnotetext{
${ }^{1}$ Статья разработана в процессе выполнения Государственной Программы (2020-2023) 20.80009.0807.21 Migrația, schimbări demografice și politici de stabilizare a situației / Миграция, демографические изменения и политики по стабилизации ситуации.

2 (CPoalelungi Olga, olga.poalelungi@gmail.com
} 
направленность эмиграционных потоков (на страны СНГ и страны ЕС) и, как следствие, различия в подходах к решению вопросов миграции в принимающих странах, что усложнило возможности общего подхода к регулированию процессами, продолжительность и интенсивность миграционных потоков, сложность учета мигрантов, находящихся за рубежом и прочее.

Основное внимание в данной статье мы уделим этапам законодательного регулирования вопросов внешней миграции (как эмиграции, так и иммиграции), на протяжение последних трех десятилетий и эффективность их применения.

Выделим основные этапы развития политик: 1990-2000 гг.; 20002010 гг. и 2010 - 2020 гг. Выделение трех этапов, разумеется, условно. Необходимо отметить что ряд молдавских исследователей в своих работах указывают периоды 1990-1005 гг.; 1996-2000 гг.; 2000 - 2006 гг.; 2013 - настоящее время. Однако, с нашей точки зрения, излишняя фрагментация сроков не позволяет произвести более полную оценку эффективности принятых политик.

Важно отметить, что на протяжении первого этапа молдавская миграционная политика была скорее реакцией на происходящие в пост - советском пространстве, а миграционные процессы отражали последствия политического и экономического кризиса в стране, результаты приватизации, банковского кризиса 1998 г. и пр. В данный период законодательство Республики Молдова большей частью было направленно на определении и формировании основных институтов государства. Так были приняты Закон «О государственной границе Республики Молдова (1990 г.)», решены вопросы гражданства (1991 г.) (Parlamentul RM, 1991), определен порядок въезда и выезда из страны и типы документов, дающих на это право (1994)1; был определен статус и права иностранных граждан и лиц без гражданства в Республике Молдова (1994 г.) (Парламент РМ, 1994). Вместе с тем законодатель в большей части был ориентирован на решение вопросов репатриации в Республику Молдова своих сограждан из других стран - бывших союзных республик, определения им гражданства, решение вопросов документирования и прочее. Инициированные на этом этапе международные, на уровне СНГ, и двухсторонние соглашения по регулированию процессов миграции также отражает данные тенденции. Среди основных документов следует отметить Соглашения о трудовой миграции с Российской Федерацией, Украиной (1993 г.), с Республикой Беларусь (1994г.), а также многосторонние соглашения на уровне СНГ

${ }^{1}$ https://www.legis.md/cautare/getResults?doc id=99482\&lang=ru Закон «О выезде из Республики Молдова и въезде в Республику Молдова (1994 г.) 
(о безвизовом режиме (1992 г.) (СНГ, 1992), о пенсионном обеспечении (1992 г.), социальной защите в случае трудового увечья (1990 г) о сотрудничестве в области трудовой миграции и социальной защиты трудящихся-мигрантов (1994 г.).

Что касается международной миграции, еще в декабре 1990 г., при СССР, был принят Закон «О миграции», определивший основные принципы внешней миграции, но который, в основном, носил запретительный характер и был направлен на защиту государства от потоков иммиграции. Впоследствии, для реализации данного закона на национальном уровне были приняты ряд постановлений Правительства ${ }^{1}$. Но поскольку на рассматриваемом этапе отсутствовали двухсторонние правовые инструменты по регулированию трудовой миграции и обеспечению основных экономических и социальных прав трудящихся мигрантов с третьими странами, указанные нормативы оказались малоэффективными. Процессы массовой эмиграции на тот момент носили нерегулируемый, нелегальный характер.

В части иммиграции ${ }^{2}$ - правовые нормы носили запретительный характер, жесткое квотирование по административнотерриториальному делению страны, что создавало препятствия для семейной, образовательной и др. типов миграции.

Несмотря на массовую эмиграцию граждан Республики Молдова в рассматриваемый период, её истинные масштабы и влияние на социальную, экономическую и демографическую ситуацию в стране, на стабильность и безопасность государства на данном этапе не признавались на политическом и законодательном уровне.

Ситуация изменилась на втором этапе с принятием Концепции государственной миграционной политики Республики Молдова ${ }^{3}$. Были определены главные цели миграционной политики, которые состоят правовом регулировании миграционных процессов и уменьшении их негативных последствий, обеспечении национальной безопасности, пресечении незаконной миграции и торговли людьми, создании равных условий для реализации прав мигрантов и обеспечения их социальной защиты. С принятием Концепции Республика Молдова вышла на

\footnotetext{
1 Постановление Правительства Республики Молдова № 717 от 24 декабря 1991 г. "Об утверждении Положения о временной трудовой деятельности граждан Республики Молдова за границей и иностранных граждан в Республике Молдова" и Постановление Правительства РМ № 1077 от 20-11-1997 «о временном трудоустройстве трудящихся-мигрантов»

2 https://www.legis.md/cautare/getResults?doc id=46885\&lang=ru\#

Постановление Правительства РМ № 1077 от 20-11-1997 «о временном трудоустройстве трудящихся-мигрантов»

3 file:///C:/Users/user1/Desktop/OP/Acte\%20normative\%20rus/HP1386 2002.html

Постановление Парламента № 1386 от 11-10-2002 «об утверждении Концепции миграционной политики Республики Молдова
} 
уровень комплексных, стратегических решений в области миграции, осуществила выбор модели управления миграционными процессами эмиграции и иммиграции, защиты прав мигрантов.

На этом этапе миграционное законодательство существенно изменилось. Так в 2002 году был принят Закон о миграции ${ }^{1}$, Закон о статусе беженцев ${ }^{2}$, в 2005 году принят Закон о предупреждении и пресечении торговли людьми. ${ }^{3}$

В то же время активизировалась деятельность государственных структур по заключению международных соглашений в области трудовой миграции, защите прав трудящихся мигрантов. В 2000-2010 годах были ратифицированы более 20 основных международных конвенций, страна стала членом Международной Организации по Миграции, Верховного Комиссара ООН по защите беженцев. Также Республика Молдова подписала двухсторонние соглашения в области трудовой миграции с Италией (2003 г.) и Республикой Азербайджан (2005 г.).

Особый импульс разработке комплексных миграционных политик придало и принятие индивидуального Плана действий по Ассоциации EC - Республика Молдова, ${ }^{4}$ принятый Правительством страны в 2005 г.

Наряду с другими разделами, План в п.2.5. предусматривал ряд мер по сотрудничеству со странами и структурами Европейского Союза в области миграции (легальной/нелегальной, по вопросам реадмиссии, визового режима, права на убежище). Реализация принятых обязательств способствовало развитию инструментов по оценке реальных объемов внешней миграции РМ; обеспечению мониторинга данных процессов; созданию базы данных о мигрантах, в том числе транзитных; совершенствованию механизмов репатриации, реадмисии, защиты прав мигрантов; усовершенствованию системы убежища; реформированию и усилению пограничной службы; введение ряда стандартов EC в национальное законодательство. Реализуемые меры позволили Республике Молдова в 2007 году подписать с ЕС Договор о реадмиссии и двухсторонние Протоколы по его имплементации со

\footnotetext{
1 https://www.legis.md/cautare/getResults?doc id=29679\&lang=ru\# Закон № 1518 от 06-12-2002 «о миграции»

${ }^{2}$ https://www.legis.md/cautare/getResults?doc id=29719\&lang=ru\# Закон № 1286 от 25-07-2002 «о статусе беженцев»

3 https://www.legis.md/cautare/getResults?doc id=107319\&lang=ru\#

Закон № 241 от 20-10-2005 «о предупреждении и пресечении торговли людьми» ${ }^{4}$ pttps://www.legis.md/cautare/getResults?doc_id=116837\&lang=roПостановление Правительства Nr. 402din 22-02-2005 «PLANUL DE ACTIIUNI* UE-MOLDOVA»
} 
странами ЕС, что послужило предпосылкой для либерализации визового режима в 2014 году.

На втором этапе развития миграционных политик наличие массовой эмиграции было признанно и на политическом уровне. Так при разработке Национальной программы "Satul Moldovenesc" (2005-2015 гг.) ${ }^{1}$, раздел IV. «Социальное развитие», пункт 4.1. «Рынок труда и миграция рабочей силы» были отмечены отрицательные последствия массовой эмиграции экономически активного населения из сельской местности что привело к ослаблению экономического потенциала страны (труда, научных исследований и инноваций).

Правительство впервые предложило программу привлечения лиц, выехавших на работу за рубеж, к решению проблем развития государства, привлечению перечислений, полученных из-за рубежа в развитие сельской местности, созданию собственных предприятий. Были установлены и определенные гарантии государства для таких предприятий. Вместе с тем, в целях эффективной защиты интересов молдавских граждан, находящихся за границей, упрощения их возвращения на родину, снижения негативного воздействия их нахождения в других странах, были предусмотрены такие меры как подписание двусторонних соглашений о социальной защите лиц, находящихся в трудовой миграции, со всеми странами, в которых находятся граждане Республики Молдова; проведение исследования по установлению числа детей, родители которых находятся за рубежом, и их потребностей, а также разработка программ поддержки детей, находящихся в тяжелых условиях ввиду отсутствия родителей в стране; установление отношений с уроженцами различных населенных пунктов страны, находящимися за границей, с целью продвижения создания молдавских сообществ за рубежом, которые будут оказывать поддержку в защите их прав и информировать о важных событиях, происходящих в Молдове (т. н. диаспора). Реализация мер данного постановления была приостановлена при смене политического руководства страны в 2009 г.

С учетом комплексного подхода к управлению миграцией, а также учитывая необходимость переложения в национальное законодательство ряда норм и директив ЕС, на данном этапе были усовершенствованы правовые инструменты управления миграцией и убежищем. В частности, в целях осуществления временной трудовой деятельности трудящимися-иммигрантами и права на временное пребывание с целью трудовой деятельности, а также условий временного трудоустройства граждан Республики Молдова за рубежом

\footnotetext{
${ }^{1}$ https://www.legis.md/cautare/getResults?doc_id=70217\&lang=ru

Постановление № 242 от 17-05-2005 «об утверждении Национальной программы "Satul Moldovenesc" (2005-2015 гг.)»
} 
был принят Закон о трудовой миграции (2008 г) $)^{1}$, усовершенствована правовая и институциональная базы функционирования системы убежища в Республике Молдова (2008 г.)2. С учетом требований Директив ЕС был принят новый Закон регулирующий въезд и выезд из Республики Молдова иностранцев, предоставление и продление им права пребывания, на репатриацию и документирование, применения мер принуждения в случае несоблюдения режима пребывания, специальные меры по учету иммиграции и др. ${ }^{3}$

Вместе с тем экономическая ситуация в стране, отсутствие рабочих мест, особенно в сельской местности, низкий размер заработной платы, по - прежнему стимулировали массовую эмиграцию трудоспособного населения. Сохранялась и интенсивность миграционных потоков. В данный период за рубежом находилось около $25 \%$ трудоспособного населения, в основном люди трудоспособного возраста $-25-35$ лет, 70 \% из них - выходцы из сельской местности. С учетом особенностей рынка труда стран назначения сложились и основные характеристики миграционного потока в страны СНГ и в страны ЕС. Так в Российской Федерации, мигранты в основном были задействованы в строительных работах, куда выезжали преимущественно молодые мужчины из сельской местности. В странах ЕC больше возможностей трудоустроиться предоставлялась надобным работникам, персоналу по уходу за престарелыми, что стимулировала выезд за рубеж женщин, в том числе с высшим медицинским и педагогическим образование. Вместе с тем, данные характеристики изменялись в зависимости от потребностей рынка труда принимающих стран, что затрудняло переговорные процессы по соглашениям в области трудовой миграции.

На этот период приходится не только рост эмиграции с целью трудоустройства, но и рост количества нелегальных мигрантов из Республики Молдова находившихся в странах ЕС. Помимо применения нелегальных схем выезда и пребывания в странах ЕС, широкое распространение принимает использование, наряду с молдавским, института множественного гражданства, особенно румынского и болгарского, стран, которые с 2004 года стали странами членами ЕС. Наличие гражданства стран ЕС существенно упрощало возможности пребывания, а с 2014 года и легального трудоустройства в странах ЕС.

\footnotetext{
1 https://www.legis.md/cautare/getResults?doc_id=112697\&lang=ru\#

Закон № 180 от 10-07-2008 «о трудовой миграции»

${ }^{2}$ https://www.refworld.org/cgi-

bin/texis/vtx/rwmain/opendocpdf.pdf?docid=520b4b9f0

Закон № 270-XVI от 18.12.2008 «об убежище в Республике Молдова»

${ }^{3}$ https://www.legis.md/cautare/getResults?doc_id=17205\&lang=ru

Закон № 200 от 16-07-2010 «о режиме иностранцев в Республике Молдова»
} 
Вместе с тем, нелегальный статус молдавских мигрантов в странах пребывания, боязнь потери работы и депортации, отсутствие реальных возможностей для возвратной/циркулярной миграции привели к более длительному пребыванию молдавских мигрантов за рубежом, ускорило процесс их адаптации и интеграции и, в конечном итоге, создало предпосылки для перехода временной миграции в постоянную. Ряд исследований молдавской диаспоры в странах ЕС подтвердили более чем 5-летний период пребывания большинства мигрантов в странах назначения, а также тенденцию воссоединения их семей (переезд детей к родителям, родителей к детям и пр.). Данные аспекты следует учитывать при анализе и разработке политик в отношении диаспоры и её роли в развитии страны и/или возможности возвращения в Республику Молдова.

Третий этап развития миграционных политик 2010 г.- настоящее время характеризуется сохранением интенсивности миграционных потоков. На данном этапе усовершенствуются механизмы комплексного управления миграцией, социальной защиты граждан РМ находящихся за рубежом, осуществляются меры по обеспечению обязательств, принятых на себя Республикой Молдова при либерализации визового режима и Договора об Ассоциации с $\mathrm{EC}^{1}$. Вместе с тем законодательство уделяет должное внимание диаспоре и привлечение её к развитию страны.

Среди важнейших правовых инструментов данного период необходимо отметить принятие Национальной стратегии в области миграции и убежища (2011-2020 годы) ${ }^{2}$. Данная Стратегия и два пятилетних плана по её реализации определила меры по комплексному, эффективному управлению миграцией, соотнесла их с политической, экономической, и социальной направленностью Республики Молдова. Согласно Стратегии, миграция требовала всеобъемлющего и последовательного менеджмента таких областей как контролируемая миграция (эмиграция, иммиграция, политики интеграции), область убежища, безгражданства, политик по предупреждению нелегальной миграции и торговле людьми, развитию инструментов контроля миграции (визовый режим, въезда и выезда в страну и пр.), учета миграции и развития современных технологий при оказании услуг. На этапе разработки Стратегия и планы её реализации были согласованны

\footnotetext{
${ }^{1}$ https://www.legis.md/cautare/getResults?doc_id=119199\&lang=ru\#

Постановление Правительства № 1472 от 30-12-2016 «об утверждении Национального плана действий по внедрению Соглашения об ассоциации Республика Молдова Европейский Союз на 2017 - 2019 годы»

2 https://www.legis.md/cautare/getResults?doc id=56020\&lang=ru

Постановление Правительства № 655 от 08-09-2011 «об утверждении Национальной стратегии в области миграции и убежища (2011-2020 годы)»
} 
со стратегиями экономического развития, Национальной стратегией демографической безопасности Республики Молдова, Стратегией занятости рабочей силы, Стратегией национального развития и др. Стратегия была разработана рабочей группой в составе представителей министерств, центральных органов власти, гражданского общества и международных организаций. Документ был основан на анализе первичных и вторичных данных, проведенном независимыми международными экспертами, включал рекомендации Международного Центра Исследования Миграционных Политик (ICMPD), Вены, Австрия.

С учетом Стратегии были усовершенствованы инструменты социальной защиты граждан РМ находящихся за рубежом, подписаны двухсторонние соглашению по переводу при возвращении в страну их социальных накоплений с Болгарией, Румынией, Люксембургом, Австрией, Эстонией, Португалией, Чехией, Бельгия и др. Были подписаны соглашения о трудовой миграции с Италией и Израилем, инициированы переговоры по подписанию подобных соглашений с Республикой Беларусь, Грецией, Литвой, Латвией, Испанией, Российской Федерацией.

Важным элементом миграционной политики на третьем этапе явилось усилении составляющей «миграция и развитие», внимание к роли диаспоры, её прямое и косвенное вовлечение в устойчивое экономическое развитие Республики Молдова. Так в 2012 г. в Правительстве было создано Бюро по связям с диаспорой, принята Программа «PARE 1+1» стимулирующая инвестицию денежных переводов мигрантов в развитие экономических проектов на уровне местного самоуправления, приняты стратегии сотрудничества с диаспорой. ${ }^{1}$ Вместе с тем необходимо отметить, что в фазе перехода от временной к постоянной миграции, оптимальные сроки более эффективного использования перечислений в инвестиционные проекты были упущены.

Либерализация визового режима со странами ЕС в апреле 2014 года одновременно явилась и стимулом для свободного передвижения граждан страны, но и вызовом для надлежащего управления процессами миграции. Так безвизовый въезд в страны ЕC, хотя и без права трудоустройства, предоставил гражданам нашей страны новые возможности для легальной миграции и для воссоединения семьи. Одновременно, как сопредельная страна со страной ЕС, Республика

\footnotetext{
1 https://www.legis.md/cautare/getResults?doc id=91207\&lang=ru

Постановление Правительства № 200 от 26-02-2016 «об утверждении Национальной стратегии «Диаспора-2025» и Плана действий по ее внедрению на 2016-2018 годы»
} 
Молдова стала притягательной для иностранцев. Это повысило ответственность за предотвращение нелегальной миграции, в том числе транзита в страны ЕС. В связи с чем РМ активизировала переговоры по подписание соглашений о реадмиссии с Казахстаном, Украиной, Арменией, Азербайджаном, другими странами, пересмотрела ряд санкций за правонарушения посягающие на режим пребывания иностранцев в Республике Молдова. В частности, санкции за недекларирование иностранными гражданами факта въезда на территорию Республики Молдова через приднестровский регион как основания для взятия их на учет. ${ }^{1}$

Вместе с тем, длительная эмиграция населения, с учетом процессов депопуляции и старения населения, привела к дефициту рабочей силы в стране, ограничила возможности иностранных инвесторов, препятствует развитию наукоемкого производства. На основании анализа Министерства труда и социальной защиты, Правительство было вынуждено инициировать ряд изменений в иммиграционном законодательстве, упростив допуск на рынок труда специалистам в области информационных технологий, высококвалифицированным работникам $^{2}$ и в предоставление упрощенного визового режима ${ }^{3}$ для ряда стран. Также, учитывая опыт миграционного кризиса 2014-2016 годов в европейских странах, власти Республики Молдова уделили повышенное внимание процессам экономической и социальной интеграции иностранцев и членов их семей ${ }^{4}$ находящихся в нашей стране.

Заключение. Эти и другие изменения в миграционном законодательстве за истекший 30-летний период свидетельствуют о том, что на сегодняшний день в Республике Молдова сформирован обширный массив правовых актов, задействованных в регулировании миграционных процессов. Можно констатировать, что по количеству нормативного материала, масштабам охватываемых ими отношений и качеству регулирования большинства областей и процедур, задействованных в миграционной сфере, этот массив не уступает аналогам других стран и отражает как национальные интересы нашей страны, так и защиту прав мигрантов. Вместе с тем необходимо отметить, что и при дальнейшей разработке и внедрении миграционных

\footnotetext{
${ }^{1}$ https://www.legis.md/cautare/getResults?doc_id=6819\&lang=ru\# Статья 333 Кодекса Республики Молдова о правонарушениях № 218 от 24-10-2008 2 https://www.legis.md/cautare/getResults?doc_id=100532\&lang=ru 3 https://www.legis.md/cautare/getResults?doc_id=112701\&lang=ru ${ }^{4}$ https://www.legis.md/cautare/getResults?doc id=124776\&lang=ru\#

Закон № 274 от 27-12-2011 «об интеграции иностранцев в Республике Молдова*»
} 
политик необходимо наличие стратегического видения экономического развития страны, с учетом её демографических проблем. Необходимо минимизировать влияние политического фактора при определении приоритетов в миграционной политике, обеспечить комплексный и последовательный подход при реализации политик, избежать их несогласованности и ведомственных интересов в условиях быстрых изменений миграционной ситуации, в том числе на региональном уровне.

\section{Литература}

Parlamentul RM. (1991). Legea Republicii Moldova cu privire la cetățenia Republicii Moldova. Nr. 596-XII din 05.06.91. Получено из https://data.globalcit.eu/NationalDB/docs/MLD\%20Law\%20596XII\%2005.06.91\%20PDF.pdf

Парламент РМ. (1994). Закон № 275 от 10-11-1994 о правовом положении иностранных граждан и лиц без гражданства в Республике Молдова. Получено из https://www.legis.md/cautare/getResults?doc_id=96950\&lang=ru

СНГ, С. г. (1992). Соглашение о безвизовом передвижении граждан государств Содружества Независимых Государств от 9 октября 1992 г. Информвационный вестник Совета глав государств и Советаглав правительств СНГ "Содружество", №7.

Douglas S.Massey. (2012). Towards and integrated model of international migration. (Eastern Jornal of European Studies, 2012, 2). Avialable at: http//

search.ebscohost.com/login.aspx?direct=true \&site=edslive $\& \mathrm{db}=$ edsd oj\&AN=edsdoj.6796d30ce8e475294363c4752994363c447

Chris Wilson, Tomas Sobotka, Lee Williamson, Paul Boyle, (2013). Migration and Intergenerational Replacement in Europe. (Population and development Rewiew/ 2013, (1). Avialable at: http// doi.org./10.1111/j.1728-4457.2013.00576.x

Dumont, Gérard-François, [Union européenne: dépopulation ou dépeuplement ?] [European Union: Depopulation or Population Decline?] (May 1, 2019). Population \& Avenir, $n^{\circ} 743$. [ISSN 0223-5706 ], Available at SSRN: https://ssrn.com/abstract=

Moraru Victor, Migrație, Diaspora, Dezvoltare: noi provocări și perspective? Chișinău, 2016: https://icjp.asm.md/sites/default/files/publicatii/migratia.pdf 
Stancu, S., and O. M. Popescu. 2018. 'International Migration: The Analysis of Economic Impact in the Globalization Context.' Economic Computation and Economic Cybernetics Studies and Research 52 (4): 79-94.

Койбаев Б.Г., Томаев Д.М. (2019). Регулирование миграционных процессов в Российской Федерации. (Теории и проблемы политических исследований /2019/Том 8).

Исследование МОМ «Доклад о миграции в мире, 2020» https://publications.iom.int/system/files/pdf/final-wmr_2020-ru.pdf 